九州大学学術情報リポジトリ

Kyushu University Institutional Repository

\title{
THE GENUS TRIMORUS FORSTER OF JAPAN (HYMENOPTERA, SCELIONIDAE)
}

Miyazaki, Minoru

Hirashima, Yoshihiro

https://doi.org/10.5109/2393

出版情報 : ESAKIA. 14，pp.79-92，1979-11-15. Entomological Laboratory，Faculty of Agriculture， Kyushu University

バージョン :

権利関係 : 


\title{
THE GENUS TRIMORUS FORSTER OF JAPAN (HYMENOPTERA, SCELIONIDAE) ${ }^{1)}$
}

\author{
Minoru MiYazaki ${ }^{2 /}$ and Yoshihiro Hirashima \\ Entomological Laboratory, Faculty of Agriculture \\ Kyushu University, Fukuoka 812, Japan
}

\begin{abstract}
The genus Trimorus Förster is recorded from Japan for the first time. Five new species, T. calvus Miyazaki, T. nigrigaster Miyazaki, T. laticlypeatus Miyazaki, T. striatissimus Miyazaki and T. fulviclavatus Miyazaki are described.
\end{abstract}

The genus Trimorus Förster is apparently the largest genus in the subfamily Teleasinae of the family Scelionidae, containing no less than 300 recorded species in the world. In the course of his study on the Japanese Scelionidae, which was made for the degree of Master of Agriculture at Kyushu University from 1969 to 1971, Miyazaki was able to find out more than 10 species of Trimorus from Japan (Hokkaido, Honshu, Shikoku and Kyushu). In this paper five of them are described as new species.

Very recently Masner (1976) published a fine monographic study of the world Scelionidae at the generic level, and provided a key to the genera of the subfamily Teleasinae, to which the present genus is belonged as mentioned above. Thanks to Masner, we can approach more easily to the Scelionidae, which are one of the least known families of the Japanese Hymenoptera. The main body of the present work, however, was done prior to him.

In regard to the terminology for the head, thorax and abdomen we referred to Richards (1956), and for the wing venation to Kieffer (1926).

We are grateful to Dr. K. Yasumatsu, Emeritus Professor, Kyushu University for his kind guidance, especially to Miyazaki in the course of his study on the Scelionidae at Kyushu University. Miyazaki is also grateful to the following entomologists for their useful advice and the gift of valuable specimens: Prof. K. Yano (Yamaguti University), Prof. S. Kimoto and Mr. K. Kanmiya

1) Contribution from the Entomological Laboratory, Faculty of Agriculture, Kyushu University, Fukuoka (Ser. 3, No. 65).

2) Present address: Hamada Branch, Shimane Agricultural Experiment Station, Hamada 697, Japan. 
(Kurume University), Dr. K. Kusigemati (Kagoshima University), Mr. A. Taketani (Kyushu Branch, Government Forest Experiment Station), Assoc. Prof. M. T. Chîjjô and Mr. K. Takeno (Kyushu University, Hikosan), Prof. T. Saigusa, Assoc. Prof. A. Nakanishi, Mr. H. Shima and Mr. 0. Yata (Kyushu University, Ropponmatsu), and Mrs. M. Yafuso (formerly Miss M. Honda) (Ryukyu University).

\section{Subfamily Teleasinae}

Masner (1976) states that the genus Trimorus is a very large genus with rather vague limits, and is nearly world-wide in distribution, flourishing mainly in temperate zones. At the same time, he recorded the genera Trisacantha Ashmead and Xenomerus Walker from Japan for the first time. So far as we know, his record of the two genera is the first contribution to the Japanese Teleasinae.

The family Scelionidae are composed of three subfamilies, Scelioninae, Teleasinae and Telenominae. The subfamily Teleasinae are unique in having the antennae 12-segmented in both sexes. The subfamily is further easily separable from the two other subfamilies by the postmarginalis of the fore wings absent, the stigmalis very short and the marginalis greatly elongated. The abdomen is also characteristic to the subfamily; it is usually rather short, more or less distinctly petiolate, the sides distinctly carinate and the third tergum by far the largest of all terga.

For the key to the genera, see Masner (1976, pp. 69-70).

\section{Genus Trimorus Förster}

Type-species: Gryonnanno Walker, 1836. Designation by Ashmead, 1893.

Trimorus Förster, 1856, Hymenopterologische Studien, 2: 101, 104.

Trichasius Provancher, 1887, Additions et corrections au volume II de la faune entomologique du Canada......Hymenopteres, $1887: 209$.

Hoplogryon Ashmead, 1893, U. S. Nat. Mus. Bull., 45: 181, 200.

Paragryon Kieffer, 1908, Ann. Soc. Sci. Bruxelles, 32: 189, 199.

Allogryon Kieffer, in Wytsman, 1910, Genera Insectorum, 80 B: 95.

Hemimorus Cameron, 1912, Soc. Ent., 27: 17, 77.

Pachyscelio Risbec, 1954, Bull. Inst. Franc. Afr. N., 16: 552.

A brief discussion of the genus was given by Masner (1976). Some common characters of Trimorus are as follows:

Head transverse. Lateral ocelli close to median ocellus in most species. Six apical segments of female antennae forming a club. Male flagellum filiform. Thorax stout. Pronotum almost invisible from above. Parapsidal furrows on mesonotum absent, or complete, or partly complete. Scutellum semicircular, unarmed with spines, smooth or partly so. Metanotum with a very 
short, rather stout spine. Propodeum short, frequently armed with a small horn at postero-lateral angles. Wing venation : subcostalis, marginalis and stigmalis present, postmarginalis absent ; marginalis very long, much longer than stigmalis. Legs slender. Abdomen constricted basally. First tergum subpetiolate. Third tergum the largest of all terga.

The genus is distinguished from other genera by the combination of the following characters :

Metanotum with one tooth or spine; parapsidal furrow, when present, not deep; legs slender; femora not thickened; and body usually well sculptured.

Trimorus is easily separable from Trisacantha, which is the nearest to the former in Japan, by the unidentate metanotum (tridentate in Trisacantha) and the normal first abdominal tergum (a distinct horn present in females of Trisacantha).

\section{KEY TO THE SPECIES DESCRIBED IN THIS PAPER}

1. Abdomen broadly oval; very small species, body less than $\mathbf{1 . 5} \mathrm{mm}$ in length $\cdots \cdots \cdots \cdots 2$ Abdomen elongate oval; larger, body more than 1. $5 \mathrm{~mm}$ in length . . . . . ................ 3

2. Parapsidal furrows complete and distinct; third tergum with longitudinal striae on its basal fourth; abdomen pale brown; scutellum brown, smooth ................calvus

- Parapsidal furrows abbreviately present on posterior half; third tergum without striae ; abdomen black; scutellum black,smooth................................. nigrigaster

3. Third tergum with more or less long, shallow striae; fourth and fifth terga faintly granulate on their basal halves; clypeus short $\ldots \ldots \ldots \ldots \ldots \ldots \ldots \ldots \ldots \ldots \ldots \ldots \ldots \ldots . . . \ldots \ldots$

- Third tergum without any striae and punctures; fourth and fifth terga without granulae ; clypeus very wide (transverse) with a few transverse distinct striae; terminal spine on metanotum triangular, surface of which is sculptured with distinct, rather deep reticulate rugae; parapsidal furrows absent ............... laticlypeatus

4. Eyes bare; antennae black; mesonotum with parapsidal furrows; sixth abdominal tergum with faint granulae on its basal half ...................... striatissimus

- Eyes pubescent; antennae brownish yellow except the club which is brown ; mesonotum with short, rather deep parapsidal furrows posteriorly; sixth ab-

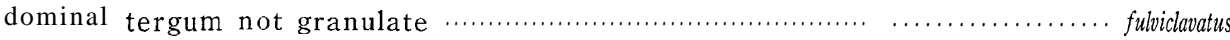

\section{Trimorus calvus Miyazaki, new species}

(Fig. 1)

This species is described based on 23 female specimens taken from 5 localities in Shikoku and Kyushu.

Female. Head as wide as thorax, pale brown, 1.5 times as high as long, about 1.9 times as wide as high. Frons with upper part smooth, faintly striated on lower fourth; several striae on lower third of frons along eye margins; lower part of paraocular areas granulate. Clypeus slightly prominent, with several distinct transverse striae. Malar space densely striate. Vertex, temples and genae smooth, not striate, clothed with short subdecumbent to decumbent golden hairs. Compound eyes small, pubescent, 3.5 to 3.8 times as 
long as malar space and 2.5 to 2.7 times as wide as genae. Lateral ocelli closely arranged, distance between lateral and median ocelli shorter than ocellocular distance (2 :3. 5). Mandibles deep reddish brown, clothed with erect to suberect golden hairs. Antennae pale reddish brown except for pedicel and base of scape with some yellowish tinge. Scape 0.6 to 0.7 times as long as pedicel and flagellum together. Pedicel rather short, 1.3 times as long as wide. Flagellum 1.3 to 1.4 times as long as scape ; funicule 0.6 to 0.7 times as long as club, relative lengths of funicular segments as $2: 2: 1: 1$; first funicular segment 1.6 to 1.7 times as long as wide, second funicular segment similar to first: relative lengths of club segments as $1.5: 2: 1.5: 1.5:$ $1.5: 2$.
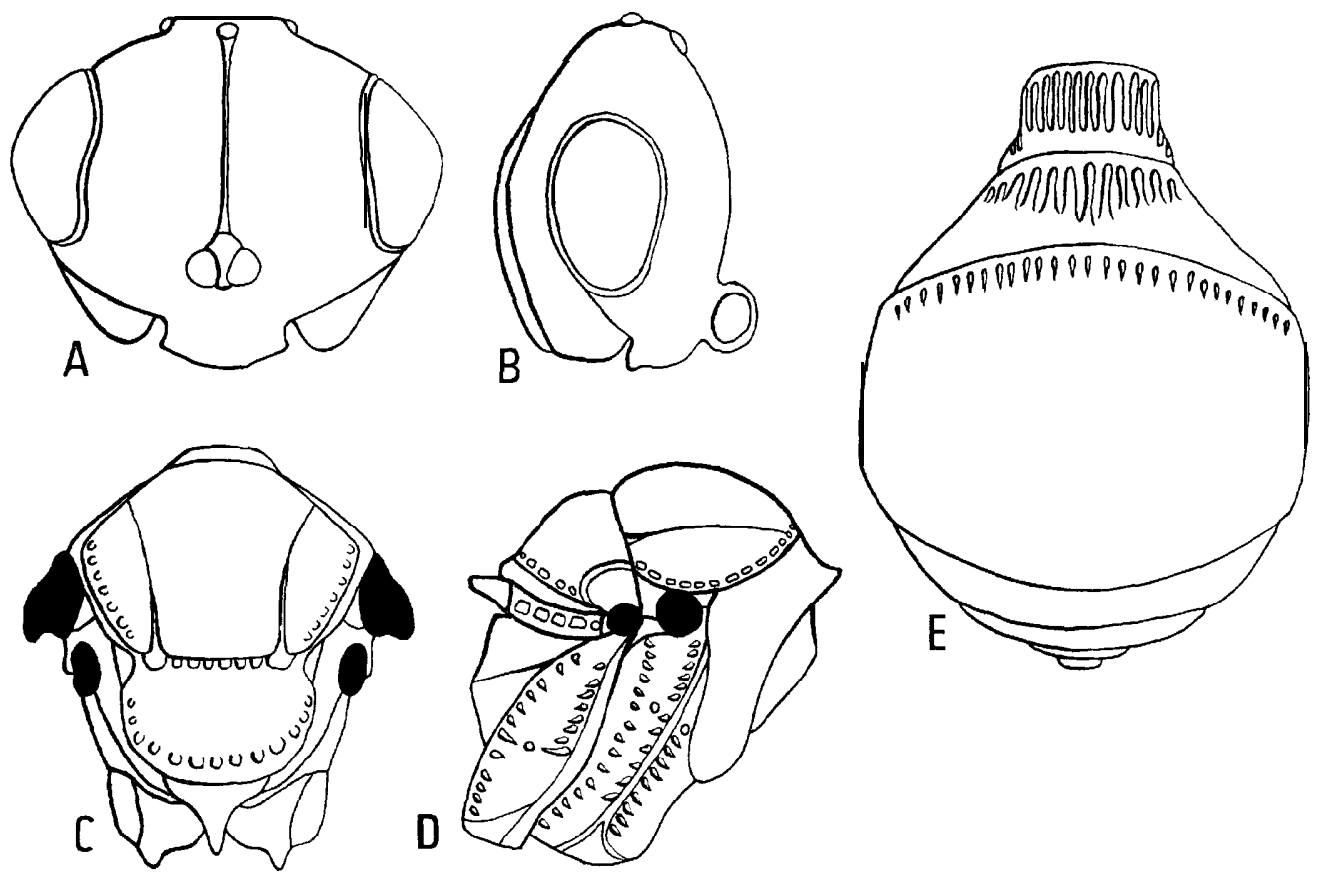

Fig. 1. Trimorus calvus Miyazaki, new species. A and B: Frontal and lateral view of head. C and D: Dorsal and lateral view of thorax. E: Dorsal view of abdomen.

Thorax pale brown, densely covered with subdecumbent to decumbent short golden hairs except for scutellum which is smooth. Propleuron brownish yellow, polished, without hairs. Pronotum weakly coriaceous on dorsal region. Mesonotum strongly convex, about 1.5 times as wide as long (13:9), with weak reticulate rugae except for posterior fifth which is smooth. Parapsidal furrows complete. Scutellum semicircular and slightly convex, polished. Mesopleuron with rows of shallow hollows along anterior and posterior margins, with a very weak median vertical carina accompanied with rows of deli- 
cate hollows behind. Metanotum with a short triangular spine. Metapleuron smooth on lower half; upper half sculptured as in mesopleuron. Propodeum with very sparse erect golden hairs. Forewings well developed, hyaline. Subcostalis 1.4 to 1 . 5 times as long as marginalis. Stigmalis very short. Legs yellowish to reddish brown.

Abdomen oval, about 1.2 to 1.3 times as long as wide. First tergum transversely trapezoidal (minimum width: maximum length as $5: 3$ ), with distinct longitudinal striae. Second tergum 1.8 to 2.0 times as long as first, with rather deep striae on its basal three-fifths. Third tergum brown, much larger than other abdominal terga, with weak longitudinal striae on its basal fourth.

Length : $0.93 \mathrm{~mm}$.

Type material: Holotype female (Type No, 2156, Kyushu Univ.) and 10 paratopotype females, Chojabaru, Mt. Kuju, Oita Pref., Kyushu, 1. VII. 1970 (M. Miyazaki) ;1 paratype female, Kajigamori, Kochi Pref., Shikoku, 25. V.1967 (M. Honda) ; 8 paratype females, Mt. Kuro, Kochi Pref., Shikoku, 28. V.1967 (M. Honda) ; 1 paratype female, Mt. Hikosan, Fukuoka Pref., Kyushu, 1. VIII. 1968 (K. Kanmiya) ; 1 paratype female, same locality as above, 8. IX.1968 (K. Kanmiya) ; 1 paratopotype female, Senomoto, Kumamoto Pref., Kyushu, 2. VII. 1970.

Distribution : Japan (Shikoku and Kyushu).

REMARKs: This small species is characteristic in having the scutellum impunctate and free of hairs, the clypeus prominent, the parapsidal furrows distinct, the third tergum weakly longitudinally striate and the abdomen rather hyaline. This species is separable from Trimorus punctifrons Kieffer, to which calvus is closely related, by the upper part of the frons smooth and impunctate.

\section{Trimorus nigrigaster Miyazaki, new species}

(Fig. 2)

This species is described based on 28 male specimens taken from 3 localities in Honshu.

Male. Head' about as wide as thorax, 1.4 to 1.5 times as high as long, approximately as wide as high, black. Frons smooth on upper half, densely striated on lower half; many striae extending upward to the middle frons along eye margins and frontal carina; frontal carina distinct. Clypeus slightly prominent, distinctly marked with a few transverse striae. Malar space not striated, smooth. Vertex with appressed hairs. Ocellar region punctate with subdecumbent hairs. Genae weakly striated and very sparsely clothed with subdecumbent to decumbent silvery hairs. Compound eyes rather small, pubescent, 3.1 to 3.2 times as long as malar space and 1.8 to 1.9 times as wide as genae. Lateral ocelli very close to median ocellus, distance between 
lateral and median ocelli much shorter than ocellocular distance (2: 4). Mandibles brownish yellow, sparsely clothed with rather long erect to suberect golden hairs. Antennae dark brown, pubescent. Scape long, about 3 times as long as wide. Pedicel very short, about as wide as long. Flagellum cylindrical, relative lengths of flagellar segments as $4.5: 4.5: 4.5: 4.5: 4.5: 5: 5.5$ : $5.5: 5: 6.5$.

Thorax black, densely clothed with decumbent to appressed silvery hairs. Propleuron smooth, without sculptures. Pronotum faintly concave, smooth. Mesonotum finely rugoso-punctate for most part and with shallow longitudinal striae on posterior fifth between parapsidal furrows. Parapsidal furrows on posterior half of mesonotum deep. Scutellum smooth, shining, with very sparse hairs. Mesopleuron with anterior or posterior margins rather broadly reticulate rugose ; lower part of mesopleuron crenulate in front of median vertical carina. Metanotum with a very short obtuse spine. Metapleuron with several strong transverse excavations on lower half. Propodeum heavily clothed with short erect to suberect silvery hairs. Fore wings well developed, about 2 times as long as abdomen. Subcostalis 1.2 to 1.3 times as long as marginalis. Legs pale to dark brown.

Abdomen black, oval, 1.3 to 1.4 times as long as wide. First tergum

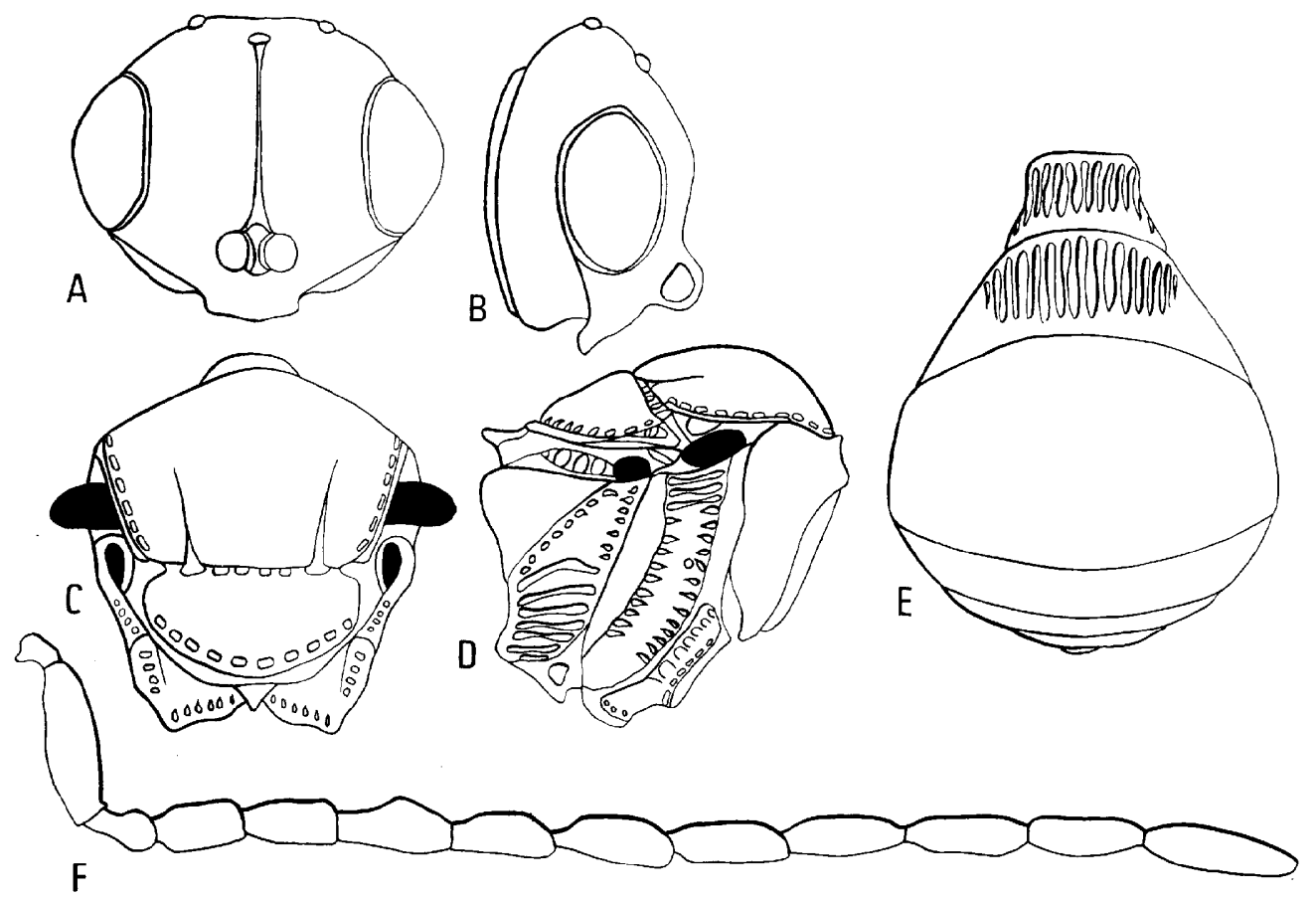

Fig. 2. Trimorus nigrigaster Miyazaki, new species. A and B: Frontal and lateral view of head. C and D: Dorsal and lateral view of thorax. E: Dorsal view of abdomen. F. Male antenna. 
transversely trapezoidal (minimum width : maximum length as $6: 4$. 2), with strong longitudinal striae on nearly entire surface. Second tergum more or less longer than first, with deep longitudinal striae on central portion. Third tergum very large, occupying almost a half of abdomen, smooth, rather densely covered with decumbent to appressed silvery hairs on lateral sides. Following four terga also smooth with sparse decumbent to appressed silvery hairs.

Length : $1.23 \mathrm{~mm}$.

Type material: Holotype male (Type No. 2157, Kyushu Univ.) and 16 paratopotype males, Togakushi, Nagano Pref., Honshu, 8. VIII. 1969 (M. Miyazaki) ; 8 paratopotype males, 8. VIII. 1969 (0. Yata) ;1 paratype male, Kaidamura, Nagano Pref., Honshu, 22. VII. 1970 (K. Kanmiya) ; 2 paratype males, Mt. Katsuragi, Nara Pref., Honshu, 25. VIII. 1969 (0. Yata).

Distribution : Japan (Honshu).

REMARKS: This small species is characteristic in the black body, the smooth malar space, the abbreviated parapsidal furrows on the mesonotum and the not striate third abdominal tergum. This species is easily differentiated from the former species Trimorus calvus Miyazaki, new species, by the combination of the black body, the incomplete parapsidal furrows on the mesonotum, the smooth third tergum and the brownish legs.

\section{Trimorus laticlypeatus Miyazaki, new species}

(Fig. 3)

This species is described based on 15 male specimens taken from 6 localities in Honshu and Kyushu.

Male. Head a little wider than thorax, 1. 2 to 1.3 times as high as long, 1.2 to 1.3 times as wide as high, black. Frons transverse, strongly striate, with the frontal carina distinct and complete. Clypeus very transverse, with a few transverse strong stirae. Malar space deeply and densely striated, Vertex longitudinally striated, the striae extending to temples. Ocellar region smooth, without hairs. Genae strongly striated, with the striae extending upward, clothed with rather long subdecumbent to "decumbent silvery hairs. Compound eyes rather small, bare, slightly prominent, 1.4 to 1.5 times as long as malar space, 1.3 to 1.4 times as wide as genae. Lateral ocelli slightly separated from eye margins, distance between lateral and median ocelli shorter than ocellocular distance $(3: 6)$. Mandibles reddish brown, very sparsely clothed with long erect to suberect silvery hairs. Antennae black. Scape about 5.3 times as long as wide. Pedicel the shortest of all the antennal segments, a little longer than wide $(3: 2)$. Flagellum slender, cylindrical, relative length of flagellar segments as $10: 10: 9: 10: 10: 11: 11: 11: 9: 10$.

Thorax black, densely clothed with short decumbent to appressed silvery 


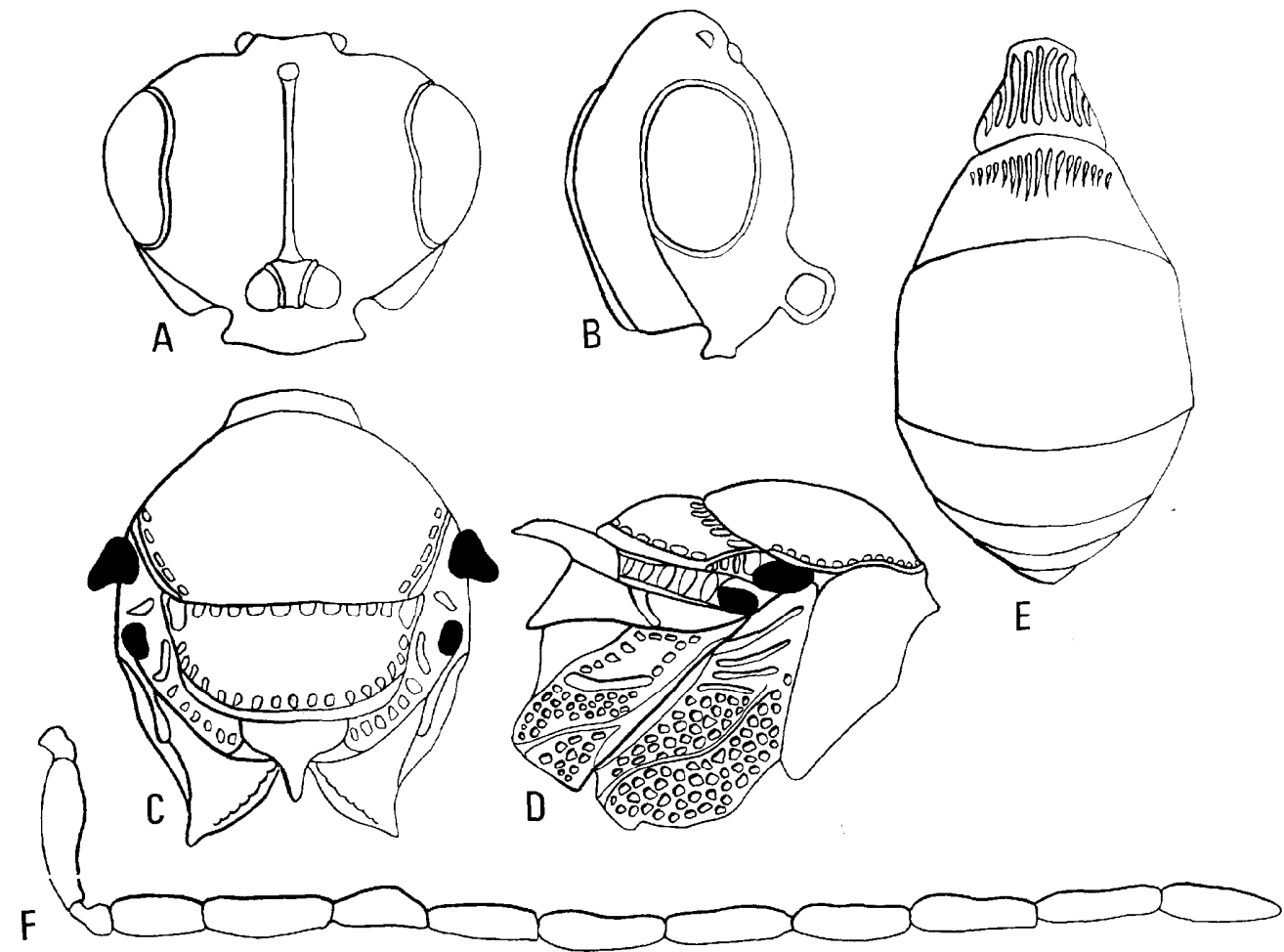

Fig. 3. Trimorus laticlypeatus Miyazaki, new species. A and B: Frontal and lateral view of head. C and D: Dorsal and lateral view of thorax. E: Dorsal view of abdomen. F. Male antenna.

hairs. Propleuron smooth, without hairs. Pronotum weakly concave, with lower half weakly striated, upper half smooth. Mesonotum 1.6 to 1.7 times as wide as long, with distinct rather deep reticulate rugae. Parapsidal furrows absent. Scutellum broad, flat, sculptured as in mesonotum except for its postero-median region which is smooth. Mesopleuron more or less sparsely foveolate-punctate. Metanotum with a triangular spine, surface of which is sculptured as in mesonotum and scutellum. Metapleuron smooth on upper half and weakly foveolate on lower half. Propodeum densely covered with erect to suberect silvery hairs. Fore wings well developed, 1.3 to 1.4 times as long as abdomen. Subcostalis about 2 times as long as marginalis. Legs reddish to dark brown.

Abdomen black, elongate oval, 1.7 to 1.9 times as long as wide. First tergum elongate (minimum width : maximum length as $6: 8.5$ ), entirely with strong longitudinal striae. Second tergum more or less longer than first (11: 8.5), striated as in first. Third tergum much larger than all other abdominal terga, without striae, sparsely clothed with decumbent to appressed silvery hairs on lateral sides. Following terga smooth, shining, sparsely clothed with 
decumbent to appressed silvery hairs.

Length : $2.00 \mathrm{~mm}$.

Type material: Holotype male (Type No. 2158, Kyushu Univ.) and 1 paratopotype male, Mt. Iide, Yamagata Pref., Honshu, 9. VIII. 1970 (M. Miyazaki) ; 1 paratype male, Mt. Katsuragi, Nara Pref., Honshu, 25. VIII. 1969 (0. Yata) ; 2 paratype males, Gokokujinja, Fukuoka City, Kyushu, 18. VI. 1969 (0. Yata) ; 1 paratype male, Mt. Wakasugi, Fukuoka Pref., Kyushu, 12. V. 1969 (0. Yata) ; 2 paratype males, same locality as above, 16. VI. 1970 (M. Miyazaki) ;1 paratype male, Mt. Hikosan, Fukuoka Pref., Kyushu, 25. VII. 1966 (A. Taketani); 1 paratype male, same locality as above, 1. VI. 1967 (S. Kimoto) ; 3 paratype males, same locality as above, 20. IV. 1969 (K. Kanmiya) ; 1 paratype male, same locality, 5. VI. 1970 (K. Kanmiya) ; 1 paratype male, Ebino-Kogen, Miyazaki Pref., Kyushu, 15. VII. 1969 (M. Miyazaki).

Distribution: Japan (Honshu and Kyushu).

REMARKS: This rather large species is very characteristic in having the clypeus very transverse, the compound eyes bare, rather small and slightly prominent, the mesonotum sparsely and strongly reticulate-rugose and the third abdominal tergum smooth. This species is easily differentiated from the related species by the metanotal spine whose surface is sculptured as in the mesonotum and the scutellum.

\section{Trimorus striatissimus Miyazaki, new species}

(Fig. 4)

This species is described based on 17 female specimens taken from 3 localities in Shikoku and Kyushu.

Female. Head as wide as thorax, 1.4 to 1.5 times as wide as long, 1.1 to 1.2 times as wide as high, black. Frons smooth on upper part, densely striated on lower third; a few striae on frons along eye margins and frontal carina strong. Clypeus rather long, distinctly marked with many transverse striae. Malar space deeply and densely striated. Vertex roughly and longitudinally striated, the striae extending toward temples. Ocellar region smooth, without hairs. Genae strongly striated and clothed with short, erect to suberect silvery hairs. Vertex, temples, genae and lower part of frons sparsely clothed with erect to suberect silvery hairs. Compound eyes large, bare, 4 to 5 times as long as malar space and 5 to 6 times as wide as genae. Lateral ocelli somewhat close to eyes, distance between lateral and median ocelli longer than ocellocular distance $(3: 2)$. Mandibles reddish brown, clothed with rather long erect to suberect golden hairs. Antennae black. Scape 0.3 to 0.5 times as long as pedicel and flagellum together. Pedicel rather long, about 2 times as long as wide. Flagellum more than 2 times as long as scape; funicle 1.2 to 1.3 times as long as club, relative lengths of funicular 


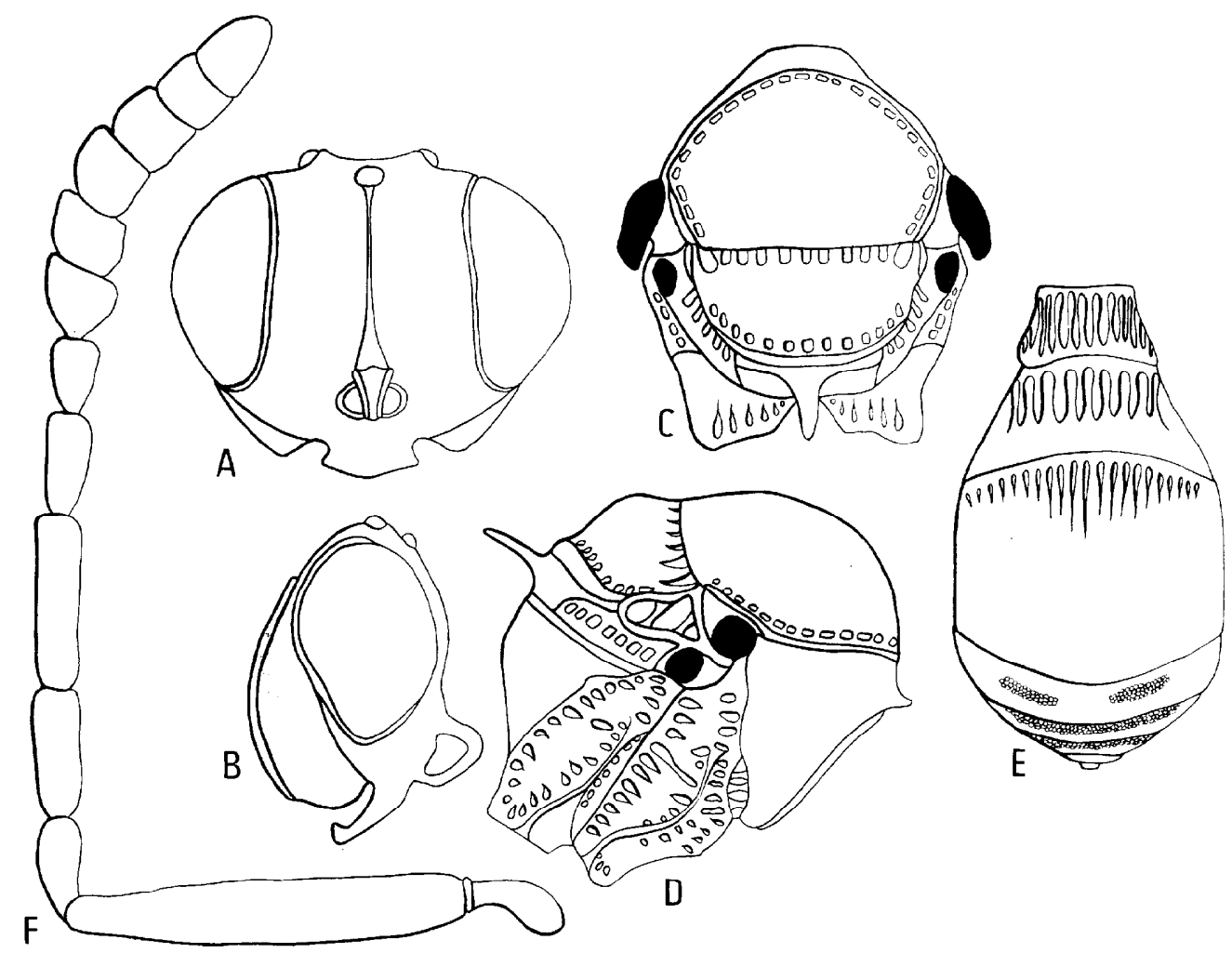

Fig. 4. Trimorus striatissimus Miyazaki, new species. A and B: Frontal and lateral view of head. C and D: Dorsal and lateral view of thorax. E: Dorsal view of abdomen. F: Male antenna.

segments as $6: 7: 5: 4$; relative length of club segments as $2: 3: 3: 3: 3: 4$.

Thorax black, rather densely covered with decumbent to subdecumbent rat'ner long silvery hairs. Propleuron coriaceous, hairy. Pronotum weakly concave at central region which is rather smooth with several vertical rugae, upper part and antero-ventral region somewhat granulate. Mesonotum a little wider than long, finely and shallowly reticulate-rugose. Parapsidal furrows absent. Scutellum semicircular and convex, reticulate nearly as in mesonotum. Mesopleuron with about 11 strong puncture-like excavations along posterior margin; median vertical carina on mesopleuron strong. Metanotum with a very long and sharp spine. Metapleuron sculptured nearly as in mesopleuron. Propodeum densely clothed with erect to suberect short silvery hairs. Fore wings well developed, about as long as body. Subcostalis 1.1 to 1.2 times as long as marginalis. Stigmalis oblique and very short. Legs yellow with some brownish tinge.

Abdomen black, elongate oval, about 2 times as long as wide. First ter- 
gum rather long trapezoidal (minimum width : maximum length as 5: 7.5), entirely with strong longitudinal striae. Second tergum more or less larger than first, with deep striae on its central portion. Third tergum larger than all other abdominal terga, occupying almost a half of abdomen, with weak striae on its central portion of basal two-thirds, decumbent to appressed long dense silvery hairs present on its lateral and latero-apical regions. Fourth to sixth terga faintly granulate.

Length : $2.06 \mathrm{~mm}$.

Type material: Holotype female (Type No. 2159, Kyushu Univ.), Mt. Inunaki, Fukuoka Pref., Kyushu, 24. VI. 1969 (M. Miyazaki) ; 1 paratype female, Kajigamori, Kochi Pref., Shikoku, 25. V. 1967 (M. Honda) ; 4 paratopotype females, 24. IV. 1967 (M. Honda) ; 6 paratopotype females, 30. IV. 1967 (M. Honda) ; 1 paratopotype female, 25. IV. 1967 (T. Saigusa) ; 2 paratopotype females, 29. V. 1969 (0. Yata) ; 1 paratopotype female, 1. V. 1970 (M. Miyazaki);1 paratype female, Mt. Hikosan, Fukuoka Pref., Kyushu, 5. VIII. 1966 (K. Takeno).

Distribution: Japan (Shikoku and Kyushu).

REMARKS: This large species is very characteristic in the bare, large and slightly prominent eyes and absence of the parapsidal furrows on the mesonotum. This species is easily differentiated from the related species by the propodeum densely clothed with fine short and silvery hairs, the abdomen elongate oval and the fourth to sixth abdominal terga coriaceous.

\section{Trimorus fulviclavatus Miyazaki, new species}

(Fig. 5)

This species is described based on 16 female specimens taken from 9 localities in Hokkaido, Honshu and Kyushu.

Femle. Head as wide as thorax, 1.3 to 1.4 times as high as long, 1.1 to 1. 2 times as wide as high, black. Frons broad, densely punctate with short, subdecumbent to decumbent silvery hairs on upper part, strongly striated on lower half, several striae along eye margin and antenna1 sockets extending upward to upper frons, lower parts of paraocular areas granulate. Clypeus rather long and transverse. Malar space densely and strongly striated. Vertex faintly longitudinally rugose, with rugae extending to temples. Ocellar region rugose as in vertex. Genae strongly strigose and clothed with short erect to suberect golden hairs. Compound eyes slightly large, with very short sparse pubescence, 2.6 to 2.7 times as long as malar space, 1.8 to 1.9 times as wide as genae. Lateral ocelli close to median ocellus, distance between lateral and median ocelli shorter than ocellocular distance (3:6). Mandibles very large, curved, clothed with rather subdecumbent to decumbent golden hairs. Antennae brownish yellow except for club which is brown. Scape rather long, 0.6 to 0.8 times as long as pedicel and flagellum together. Pedicel 


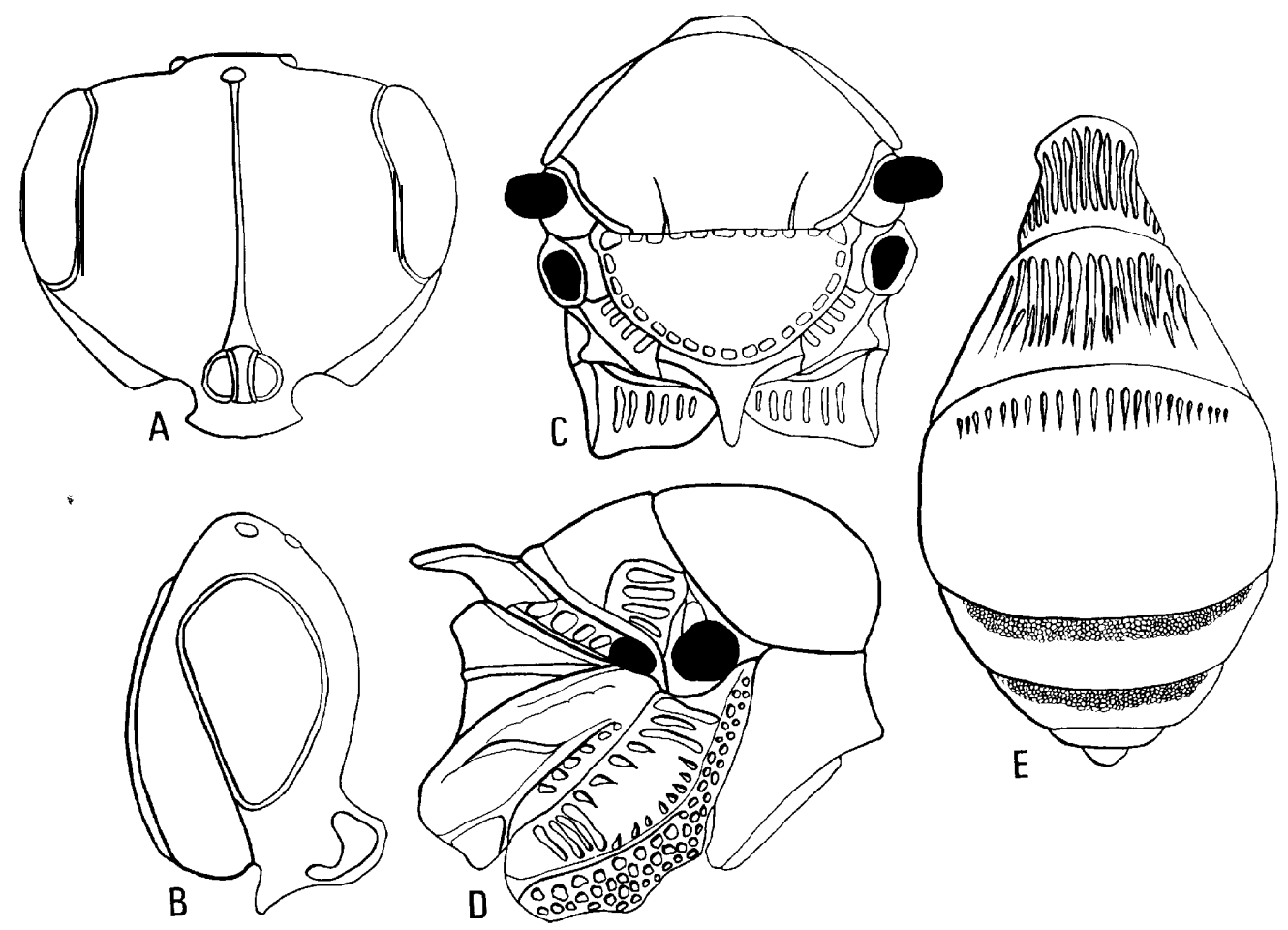

Fig. 5. Trimorus fulviclavatus Miyazaki, new species. A and B: Frontal and lateral view of head. C and D: Dorsal and lateral view of thorax. E: Dorsal view of abdomen.

about a fifth as long as scape, 2 times as long as wide. Flagellum 1.3 to 1.4 times as long as scape; funicle 0.8 to 0.9 times as long as club, relative lengths of funicular segments as $7: 7: 2.5: 2.5$; first funicular segment 2 times as long as wide, second funicular segment as wide as first, club brown, relative lengths of club segments as $3: 3: 3: 3: 3: 3.5$.

Thorax dark brown, densely clothed with long subdecumbent to decumbent silvery hairs. Propleuron coriaceous with appressed silvery hairs. Ventral region of pronotum strongly concave, with weak longitudinal striae; dorsal part of pronotum strongly concave, with weak longitudinal striae; dorsal part of pronotum somewhat reticulate rugose. Mesonotum 1.8 to 1.9 times as wide as long, entirely rugoso-punctate with long subdecumbent to decumbent golden hairs. Parapsidal furrows shortly present posteriorly. Scutellum slightly broad, convex, rugoso-punctate as in mesonotum except for posteromedian portion smooth and shining. Mesopleuron strongly sculptured; posterior half of mesopleuron with puncture-like transverse excavations ; anterior half of mesopleuron with dense foveolate-punctures, hairy throughout. Metanotum with a rather long and wide triangular spine, surface of which is concave, without distinct sculptures. Metapleuron smooth and shining on upper 
half, and weakly longitudinally striate on lower half. Propodeum longitudinally canaliculate, rather densely clothed with erect to suberect silvery hairs. Fore wings developed, about 1.2 times as long as abdomen. Subcostalis 2.2 to 2. 3 times as long as marginalis. Stigmalis very short. Legs deep yellow.

Abdomen dark brown, elongate oval, 1.7 to 1.8 times as long as wide. First tergum long trapezoidal (minimum width : maximum length as 9.2 :11), strongly and longitudinally striated. Second tergum striated as in first. Third tergum much larger than all other abdominal terga, with faint long longitudinal striae on basal two-thirds ; hairs on lateral sides of third tergum decumbent to appressed, sparse, silvery. Fourth to fifth terga finely granulate except for apical portions.

Length : $2.56 \mathrm{~mm}$.

Type material: Holotype female (Type No. 2160, Kyushu Univ.) and 1 paratopotype female, Berabonai, Ashoro, Tokachi Prov., Hokkaido, 22. VII. 1967 (A. Nakanishi) ; 1 paratopotype female, 24. VII. 1967 (M. Honda) ; 1 paratype female, Iwaobetsu, Mt. Rausu, Hokkaido, 5. VIII. 1967 (T. Saigusa) ; 1 paratype female, Karasawa, Ashoro Prov., Hokkaido, 21. VII. 1967 (A. Nakanishi) ; 2 paratype females, Shiraike, Niigata Pref., Honshu, 18. VII. 1966 (M. Honda) ; 1 paratype female, Kutsukake, Nagano Pref., Honshu, 9. VII. 1966 (M. Honda);1 paratype female, same locality as above, 10. VII. 1966 (M. Honda) ; 1 paratype female, Mt. Inunaki, Fukuoka Pref., Kyushu, 29. V. 1969 (M. Miyazaki) ; 1 paratype female, same locality as above, 19. X. 1969 (M. Honda) ;1 paratype female, Mt. Hikosan, Fukuoka Pref., Kyushu, 13. VI. 1966 (K. Takeno); 1 paratype female, same locality as above, 11. VII. 1969 (K. Kanmiya) ; 1 paratype female, Mt. Wanizuka, Kyushu, 23. V.1966 (K. Kusigemati).

Distribution: Japan (Hokkaido, Honshu and Kyushu).

REMARKS: This species is the largest of the five species described in this paper and is very characteristic in having the punctate frons, the yellow antennae with a brown club, the concave spine of metanotum, the elongate oval abdomen and the coriaceous fourth and fifth abdominal terga. This species is easily differentiated from the related species by the combination of characters stated above.

\section{References}

Brues, C. T. (1908) Hymenoptera Fam. Scelionidae. Genera Insectorum, fasc. 80 a: 1-59, 2 pls.

Eady, R. D. (1968) Some illustrations of microsculpture in the Hymenoptera. Proc. Roy. ent. Soc. London 43 (4-6) : 66-72.

Fouts, R. M. (1948) Parasitic wasps of the genus Trimorus in North America. Proc.U. S. Nut. Mus. 98 (3225) : 91-148.

Kieffer, J. J. (1910) Hymenoptera, Fam. Scelionidae. Addenda et corrigenda. Genera Insectorum, fasc. 80 b: 61-112, 1 pl.

Kieffer, J. J. (1926) Scelionidae. Das Tierreich 48: 173-264. 
Masner, L. (1962) On the Trimorus-species of the ninus (Nixon)-group. (Hymenoptera: Scelionidae). Acta Zool. Acad. sci. Hung. 8 (1-2) : 107-113.

Masner, L. (1965) The type of Proctotrupoidea (Hymenoptera) in the British Museum (Natural History) and in the Hope Department of Entomology, Oxford. Bull.Brit. Mus. (Nat. Hist.) Ent. London, Supplement 1: 100- 108.

Masner, L. (1976) Revisionary notes and key to world genera of Scelionidae (Hymenoptera : Proctotrupoidea). Mem. Ent. Soc. Canada (97) : 1-87.

Muesebeck, C. F. W. and L. M. Walkley (1951) Family Scelionidae. In Muesebeck, C. F. W., K. V. Krombein and H. K. Townes, Hymenoptera of Amerisa North of Mexico Synoptic Catalog. U. S. Dept. Agr., Agr. Monogr. No. 2: 690-706.

Muesebeck, C. F. W. (1958) Family Scelionidae. In Krombein, K. V., Hymenoptera of America North of Mexico Synoptic Catalog (Agr. Monog. No. 2) First Supplement: 92-93.

Muesebeck. C. F. W. and L. Masner (1967) Family Scelionidae. In Krombein, K. V., Hymenoptera of America North of Mexico Synoptic Catalog (Agr. Monog. No. 2) Second supplement : 296-300.

Nixen, G. E. J. (1936) The African species of Teleasinae (Hym., Proctotrupoidea, Fam. Scelionidae). Ann. Mag. nat. Hist. (10) $17:$ 114-141, 161- 191.

Richards, 0. W. (1956) Hymenoptera. Introductions and Key to Families. Handbooks for the Identification of British Insects. Roy. Ent. Soc. London 6 (1) : I-94.

Szabó, J. B. (1966) Ökologische, ethologische und systematische Untersuchungen an paläarktischen Teleasinen (Hym., Scelionidae). Folia ent. Hung. (S. N.), 19 (2) : 9-108. 